\title{
Don't Bite the Hand That Feeds You: Late Complication of Mitral Valve Replacement
}

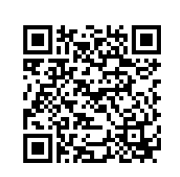

\author{
Amena Nayeem, Muhammad Fahad Zakir*, Sumera Nawaz Qabulio, Ghania Niazi and Fasiha Sohail \\ Ziauddin University and Hospital, Pakistan
}

Submission: January 22, 2018; Published: May 24, 2018

*Corresponding author: Muhammad Fahad Zakir, Ziauddin University and Hospital, Karachi, Pakistan, Tel: +92-333-2324002;

Email: fahad_bawani@hotmail.com

Abstract

Case: A 42-year old married female, known case of mitral regurgitation and chronic atrial fibrillation with mitral valve replacement in 2007 (on warfarin) with complaints of left sided motor and facial weakness. CT brain was done which showed ischemic changes.

On exam: GCS 12/15 (E4, M6, V2). Power in left upper and lower limb was $2 / 5$. Tone in the left side was decreased. Reflexes of the left side were exaggerated. Plantars on the left side were up going. Neurological exam of the right side was normal. Gag reflex was absent and cranial nerve VII examination of the left side showed weakness.

Management: Nasogastric tube and Foleys catheter were passed. Initial treatment with Tab Aspirin $75 \mathrm{mg}$, tab atorvastatin $20 \mathrm{mg}$, tab clopidogrel $75 \mathrm{mg}$. tab digoxin $0.25 \mathrm{mg}$ tab bisoprolol (fumarate) $2.5 \mathrm{mg}$ were added to the treatment. time.

Outcome: Patient was discharged on the fifth day with improved symptoms and advised daily physiotherapy and a follow up in one week's

Keywords: MVR; Mitral valve replacement; Mitral regurgitation; Valve replacement; Biological prosthesis; Mechanical prosthesis; Don't bite the hands that feed you

\section{Introduction}

Mitral valve regurgitation is the most frequently occurring valvular heart defect in the US and may be brought on by the degenerative changes of aging, ischemic mitral regurgitation or rheumatic disease and is the second most common valvular defect in adults. Intervention is required when there is ventricular dysfunction, NYHA class II symptoms or a change in the normal end systolic diameter [1]. In patients with mitral valve regurgitation valve replacement is the treatment of choice. Bio prostheses or mechanical prostheses are used depending on the patient's age and other related conditions. These replacement surgeries carry both early and long term complications, one of them being stroke. Stroke can be defined as signs of focal neurological deficit due to an acute injury to the brain caused by a vascular event; it can either be hemorrhagic or ischemic in etiology [2]. In this report the case of a 42 year old woman with mechanical mitral valve prosthesis has been discussed.

\section{Case Presentation}

A 42-year old married female, known case of mitral regurgitation and chronic atrial fibrillation with mitral valve replacement in 2007 (on warfarin) presented to the ER with complaints of left sided motor and facial weakness for one day. She suffered a fall our days earlier, after which she was rushed to a government hospital and a brain CT was done, which was unremarkable and she was sent home after primary management. One day later she developed left sided facial and motor weakness (hemiparesis) and was again taken to a government hospital and a brain CT was repeated which showed ischemic changes. Primary management given to the patient also included these drugs: digoxin, amiloride, furosemide, dimenhyrinate, diclofenac sodium, atorvastatin and verapamil (hcl). After the patient did not show any progress she was brought into our set-up and admitted into the intensive care unit.

A. Primary assessment: vitals were normal and GCS was 12/15 (E4, M6, V2).

B. Neurological exam: Power in left upper and lower limb was $2 / 5$. Tone in the left side was decreased. Reflexes of the left side were exaggerated. Plantars on the left side were up going. Neurological exam of the right side was normal. Gag reflex was absent and cranial nerve VII examination of the left side showed weakness. 
C. Respiratory exam: Chest had harsh vesicular breathing

D. Precordium exam: $s 1+s 2$ with metallic click in the mitral region

E. Genitourinary exam: unremarkable

\section{Laboratory findings}

Baseline tests showed that her Hb was 12, TLC 9.17, platelets 282. Na 144, K 4.1, Cl 109, urea/creatinine 13/0.8, total bilirubin 0.79 , SGPT 14, and Alk PO4 72. Urine D/R: pH 6.5, sp gravity 1.030, albumin +++ , WBC 10-12, RBC 15-20, nitrites +. PT and INR 12 and 1.0. Blood culture done showed no growth.

\section{Diagnostic imaging and ECG}

MRI showed Right middle cerebral artery infarct. Echo showed enlarged left and right atrium, normal right and left ventricle, Ejection fraction $60 \%$, no paravalvular leak. MS (mild to moderate), MR (trace), increase flow on LVOT seen. AR (mild), no AS, TR (moderate) with moderate PAA and PR (trace). ECG, showed rate controlled atrial fibrillation,

\section{Management}

Nasogastric tube and Foleys catheter were passed and strict I/o charting was done. Initial treatment given was Tb Aspirin $75 \mathrm{mg}$, tb atorvastatin $20 \mathrm{mg}$, tbclopidogrel $75 \mathrm{mg}$. On the second and third day patient remained oliguric despite the hydration GCS was 15/15. Warfarin was stopped, Capsule omeprazole $40 \mathrm{mg}$, tb digoxin $0.25 \mathrm{mg}$ tbbisoprolol (fumarate) 2. $\mathrm{mg}$ and tb furosemide $40 \mathrm{mg}$ were added to the treatment. Subsequently digoxin was decreased to $0.25 \mathrm{mg}$.

\section{Outcomes}

On the fourth day patient was responding well but speech remained slurred, gag reflex improved slightly. Patient was discharged on the fifth day with improved symptoms and advised daily physiotherapy and a follow up in one week's time.

\section{Discussion}

Mitral valve replacement surgery has early and late complications. Our case is slightly similar to a case reported by Thomas et al, where an elderly woman had a stroke following an open MVR surgery involving embolisation of heart tissue, was the first to be reported [3]. The patient in the above mentioned case had an early complication. Our patient suffered an embolic event ten years post valve replacement surgery with a similar presentation however there was no evidence of thrombus. Age, heart failure, atrial fibrillation, hypertension, smoking and diabetes are risk factors that can lead to a thromboembolic stroke or even a hemorrhagic stroke [4]. Patients who undergo mitral valve replacement with correction of atrial fibrillation have reduced chances of developing a stroke whereas those with only valve replacement have been shown to be susceptible to a thromboembolic event up to 8 years after surgery.

There are a myriad of explanations for the development of stroke in our patient. Patients who undergo valve replacement surgery and have mechanical valve prostheses or even chronic atrial fibrillation should have a target PT or INR more than 2.5 to 3.5 times of the normal value after the surgery and should be on warfarin [5]. Considering the risk factors, the normal range of INR and PT in the patient and the chronic atrial fibrillation may have contributed to stroke as a late complication [6]. Embolic stroke can occur in a patient within $6.6 \pm 4$.6 years after an MVR surgery [4]. Additionally, tricuspid regurgitation, if left uncorrected can lead to right ventricular enlargement over the years resulting in right-sided heart failure [7].

The role of anticoagulation to prevent thromboembolic events is crucial; combining with that, inadequate medication to a non-compliant patient may play a role in determining whether this was the cause of the event. The management after MVR surgery is the initiation of warfarin therapy as it reduces the risk of thromboembolism. While the patient is on warfarin target PT and INR should be closely monitored. Although, the risk of embolic and hemorrhagic stroke is high in patients with mechanical valve prostheses, mortality is low in middle aged patients [5]. We believe that is the first case to report an embolic stroke as a late complication of mitral valve replacement surgery with mechanical valve prosthesis in a middle aged patient. Cases that have been reported discuss older patients with early complications.

\section{References}

1. Madesis A, Tsakiridis K, Zarogoulidis P, Katsikogiannis N, Machairiotis $\mathrm{N}$, et al. (2014) Review of mitral valve insufficiency: repair or replacement. J Thorac Dis 6(1): S39-S51.

2. Prasad K, Kaul S, Padma MV, Gorthi SP, Khurana D, et al. (2011) Stroke management. Ann Indian Acad Neurol 14(1): S82-S96.

3. Thomas MC, Delgado JE, Todd AJ, Young ML, Fease JL, et al. (2017) A case of right middle cerebral artery 'tendonectomy' following mitral valve replacement surgery. BMJ Case Rep doi: 10.1136/bcr-2016012951.

4. Ruel M, Masters RG, Rubens FD, Bédard PJ, Pipe AL, et al. (2004) Late incidence and determinants of stroke after aortic and mitral valve replacement. Ann Thorac Surg 78(1): 77-83.

5. Kulik A, Bédard P, Lam BK, Rubens FD, Hendry PJ, et al. (2006) Mechanical versus bioprosthetic valve replacement in middle-aged patients. Eur J Cardiothorac Surg 30(3): 485-491.

6. Bando K, Kobayashi J, Hirata M, Satoh T, Niwaya K, et al. (2003) Early and late stroke after mitral valve replacement with a mechanical prosthesis: risk factor analysis of a 24-year experience. J Thorac Cardiovasc Surg 126(2): 358-364.

7. Groves P (2001) Valve disease: Surgery of valve disease: late results and late complications. Heart 86(6): 715-721. 
Your next submission with Juniper Publishers will reach you the below assets

- Quality Editorial service

- Swift Peer Review

- Reprints availability

- E-prints Service

- Manuscript Podcast for convenient understanding

- Global attainment for your research

- Manuscript accessibility in different formats

( Pdf, E-pub, Full Text, Audio)

- Unceasing customer service

Track the below URL for one-step submission https://juniperpublishers.com/online-submission.php 